\title{
Entender las experiencias de transición educativa
}

\author{
Aina Tarabini ${ }^{1}$
}

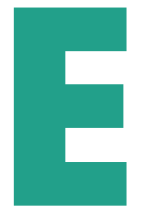

1 estudio de las elecciones y las transiciones educativas de los y las jóvenes tiene una importante tradición de investigación sociológica tanto a nivel nacional como internacional. Son numerosos los estudios que han señalado el impacto de los profundos cambios socio-económicos, políticos y culturales del capitalismo tardío sobre la vida de los y las jóvenes en general y sobre su forma de experimentar la educación y desarrollar sus elecciones y transiciones educativas en particular (Furlong, 2009; Tarabini y Ingram, 2018; Wyn y White, 1997). En las sociedades contemporáneas, las trayectorias educativas de los y las jóvenes son mucho más complejas y diversas de lo que eran en las sociedades industriales. Aspectos de contingencia, reversibilidad y falta de predictibilidad marcan, hoy en día, las transiciones de los y las jóvenes a nivel internacional (Walther, 2006). Y, sin embargo, ello no implica que los parámetros de desigualdad social hayan perdido relevancia para explicar y abordar dicho problema sociológico. Al contrario, a mediados de los años noventa Furlong y Cartmel (1997) ya señalaron que poner un énfasis excesivo en la naturaleza individual de las elecciones y transiciones educativas corría el riesgo de negligir el permanente impacto de las desigualdades sociales, y en particular de la clase social, en la vida de los y las jóvenes. Es lo que los autores llamaron, la falacia epistemológica de la modernidad tardía, aquella que crea la ilusión de igualdad, a la vez que esconde la persistencia de la desigualdad.

Este monográfico se centra en el estudio de las elecciones y transiciones educativas desde el punto de vista de las perspectivas, experiencias, vivencias y representaciones de los y las jóvenes. Este objetivo se enmarca en una triple perspectiva: en primer lugar, el monográfico pretende alejarse de aquellas perspectivas que transmiten una imagen de la juventud y sus experiencias educativas como excesivamente homogéneas y monolíticas; reflejar la diversidad de formas de vivir y dar sentido a las elecciones educativas es, pues, un objetivo común de todos los artículos que componen el monográfico. En segundo lugar, el monográfico muestra como los y las jóvenes negocian y dan sentido a sus elecciones y transiciones educativas, dentro de contextos socioculturales, institucionales y escolares particulares; en este sentido, el foco específico en los y las jóvenes no se puede desvincular de sus contextos de referencia y así lo ponen de manifiesto, de forma individual y colectiva, todos los artículos que se incluyen en este número. En tercer lugar, el monográfico se aleja explícitamente de los enfoques que abordan las elecciones y transiciones educativas desde la retórica del individualismo y la elección racional y, en cambio, propone un enfoque que entiende la propia elección como un proceso marcado por relaciones y emociones, a partir del cual

1 Aina Tarabini, Universidat Autònoma de Barcelona, aina.tarabini@uab.cat. 
los y las jóvenes -explicita e implícitamente- se definen a sí mismos en relación a los otros, se distinguen y se (re)significan (Reay, et al., 2001).

De este modo, los seis artículos que componen el monográfico evidencian cuatro grandes aspectos para el estudio de las transiciones educativas de los y las jóvenes que contribuyen a reforzar y ampliar la investigación realizada hasta el momento en este campo de estudio:

En primer lugar, todos los artículos permiten desmontar los discursos hegemónicos que entienden las elecciones y transiciones educativas de los y las jóvenes como fruto de un proceso mayormente individual, libre y racional. Frente a un relato dominante que exacerba las responsabilidades individuales en las trayectorias de los y las jóvenes, los seis artículos del monográfico muestran el impacto persistente de los ejes de desigualdad social -específicamente, la clase social, el género y el origen- sobre los procesos de elección y transición. La desigualdad social se refleja en las oportunidades, las disposiciones, las aspiraciones y los imaginarios de los y las jóvenes, generando escenarios profundamente dispares para realizar sus transiciones educativas.

En segundo lugar, todos los artículos del monográfico ponen de manifiesto el rol central que juegan las estructuras institucionales para habilitar o inhabilitar diferentes transiciones educativas entre los y las jóvenes. Aspectos como la estructura de los sistemas educativos, la oferta de diferentes opciones formativas, las culturas de enseñanza de diferentes etapas educativas o el prestigio institucional de diferentes itinerarios educativos son elementos clave para entender las oportunidades de transición de los y las jóvenes dentro del sistema educativo y hacia el mercado laboral. Estas estructuras no sólo configuran diferentes oportunidades de transición entre diferentes perfiles de jóvenes, sino que además conforman imaginarios de itinerarios 'normalizados' y 'subsidiarios' y proyectan imágenes de éxito y fracaso en los procesos de elección educativa de los y las jóvenes.

En tercer lugar, los artículos del monográfico muestran el papel específico que juega el profesorado como agente clave para entender los procesos de transición y elección educativa de los y las jóvenes. Las expectativas docentes, la percepción de apoyo docente por parte de los estudiantes o las prácticas de acompañamiento y orientación son elementos centrales para entender el rol activo que juegan los centros educativos en la (re)producción o transformación de las desigualdades sociales en los procesos de transición educativa. Los y las docentes construyen y proyectan imágenes sobre los diferentes itinerarios educativos y sobre las capacidades y habilidades de su alumnado que funcionan como poderosas profecías que se cumplen a sí mismas, (im)posibilitando, material y simbólicamente, diferentes trayectorias educativas entre los y las jóvenes.

Finalmente, los artículos del monográfico ponen de manifiesto que, si bien es absolutamente necesario analizar el impacto de las estructuras sociales e institucionales sobre las transiciones educativas de los y las jóvenes, el análisis aislado de dichas estructuras es por sí mismo insuficiente. De hecho, los actores sociales experimentan, negocian y (re)significan dichas estructuras de formas muy variadas en función de sus perfiles, trayectorias e identidades. Es, por tanto, en la relación entre lo que permiten las estructuras sociales, institucionales y escolares y la forma a través de la cual los y las estudiantes viven dichas estructuras donde se debe situar el análisis de las transiciones educativas. Así pues, los artículos del demográfico demuestran que para entender lo que Billett et al., (2012) definen como 'transiciones productivas' es imprescindible presentar atención a las experiencias subjetivas de los y las jóvenes. Unas experiencias 
que, como se ha afirmado en esta introducción y cómo se desarrolla a lo largo de los seis artículos que componen el monográfico, no pueden entenderse de forma aislada, sino que deben abordarse siempre de forma relacional.

El valor añadido del monográfico al campo de estudio de las transiciones educativas es, pues, su capacidad para desplegar esta mirada relacional que se aleja simultáneamente de enfoques excesivamente individualistas y excesivamente estructuralistas. Las transiciones educativas son siempre el resultado de una agencia socialmente situada (Evans, 2007; Heinz, 2009) donde interactúan de formas múltiples y variadas los elementos individuales y estructurales. $\mathrm{Y}$ es en esta relación entre estructuras, instituciones y experiencias donde debe situarse el foco de análisis para una comprensión profunda de los procesos de elección y transición educativa de los y las jóvenes.

\section{Referencias bibliográficas}

Billett, Stephen; Sim, Cheryl; Johnson, Greer; Thomas, Sue; Hay, Stephen y Ryan, Jill (Eds) (2012). Experience of School Transitions. Policies, Practice and Participants. London: Srpinger

Evans, Karen (2007): "Concepts of Bounded Agency in Education, Work, and the Personal Lives of Young Adults". International Journal of Psychology, 42(2), 85-93. DOI: https://doi. org/10.1080/00207590600991237.

Furlong, Andy (Ed) (2009). Handbook of Youth and Young Adulthood. New Perspectives and Agendas. New York: Routledge.

Furlong, Andy y Cartmel, Fred (1997). Young People and Social Change: Individualisation and Risk in Late Modernity. Buckingham: Open University.

Heinz, Walter R. (2009): "Structure and Agency in Transition Research". Journal of Education and Work, 22 (5), 391-404. DOI: https://doi.org/10.1080/13639080903454027.

Reay, Diane; Davies, Jacqueline; David, Miriam y Ball, Stephen J. (2001): “Choices of Degree or Degrees of Choice? Class, 'Race' and the Higher Education Choice Process”. Sociology, 35 (4), 855-874. DOI: https://doi.org/10.1017/S0038038501008550.

Tarabini, Aina y Ingram, Nicola (2018). Educational Choices, Transitions and Aspirations in Europe: Systemic, Institutional and Subjective Challenges. Londres: Routledge.

Walther, Andreas (2006): "Regimes of Youth Transitions. Choice, Flexibility and Security in Young people’s Experiences Across Different European Contexts”. Young, 14,119-139.

Wyn, Johanna y Whyte, Rob (1997). Rethinking Youth. Sydney: Allen \& Unwin. 